\title{
Synthesis of $\quad \mathrm{NaLuF}_{4}: \mathrm{Er}^{3+}, \quad \mathrm{Yb}^{3+}, \quad \mathrm{Ce}^{3+}$ nanoparticles and study of photoluminescent properties in C - band
}

\author{
K.V. Khaydukov ${ }^{1, *}$, V.V. Rocheva ${ }^{1}$, A.G. Savelyev ${ }^{1}$, M.E. Sarycheva ${ }^{2}$, and \\ I.M. Asharchuk ${ }^{1}$ \\ ${ }^{1}$ FSRC "Crystallography and Photonics" RAS, "Institute of Photonic Technology" RAS, 108840 \\ Troitsk, Moscow, Russia \\ ${ }^{2}$ Moscow Technological University, 119571 Moscow, Russia
}

\begin{abstract}
The novel core@shell nanocrystals $\beta-\mathrm{NaLuF}_{4} @ \mathrm{NaLuF}_{4}$ codoped with rare-earth ions $\mathrm{Er}^{3+}, \mathrm{Yb}^{3+}, \mathrm{Ce}^{3+}$ have been synthesized. The nano-particles indicate the intensive lines of anti-Stokes luminescence in the telecommunication C - band of spectrum when pumped at $970-980 \mathrm{~nm}$. The nanoparticles have been characterized by transmission electron microscopy and spectrofluorimetry. The nanoparticles have a size $40-80$ $\mathrm{nm}$ and possess the intensive photo-luminescence $73 \mathrm{~nm}$ bandwidth centered around $1530 \mathrm{~nm}$. The photo-luminescence kinetics of $\beta-\mathrm{NaLuF}_{4}$ : $\mathrm{Er}^{3+} / \mathrm{Yb}^{3+} / \mathrm{Ce}^{3+}$ has been studied in IR range of spectrum. We have demonstrated that doping with cerium ions prevents serial stepwise excitation of erbium ions. Consequently, the lifetime of transition in erbium ${ }^{4} \mathrm{I}_{13 / 2} \rightarrow{ }^{4} \mathrm{I}_{15 / 2}$ has risen up to $6.9 \mathrm{~ms}$. Intensity of $1530 \mathrm{~nm}$ line in $\mathrm{Er}^{3+}$ ions excited at $980 \mathrm{~nm}$ has been increased up to 6 times. Therefore, the nanoparticles are applicable to fabrication of compact waveguide amplifiers for $\mathrm{C}$ - band.
\end{abstract}

\begin{abstract}
Nano-sized phosphor crystals form a new generation of nanomaterials as they possess the unique optical properties attractive for applications in telecommunications technology, integrated optics and photonics. The unique luminescent properties of nanophosphors are the result of successive absorption of photons by ytterbium ions and resonant non-radiative energy transfer to the erbium ions within the matrix of the hexagonal $\beta-\mathrm{NaLuF}_{4}$ phase inorganic nanocrystal [1]. Figure 2 shows the energy level diagram of the crystal $\mathrm{NaLuF}_{4}$ : $\mathrm{Er}^{3+} / \mathrm{Yb}^{3+} / \mathrm{Ce}^{3+}$ explaining the down-conversion mechanism of $980 \mathrm{~nm}$ radiation. The pump photon at $980 \mathrm{~nm}$ is absorbed by the ion $\mathrm{Yb}^{3+}$, transferring the latter into the excited state ${ }^{2} \mathrm{~F}_{5 / 2}$. As a result of non-radiative resonance energy transfer, level ${ }^{4} \mathrm{I}_{13 / 2}$ of $\mathrm{Er}^{3+}$ is populated with the possibility of subsequent excitation of overlying energy states. Ions $\mathrm{Ce}^{3+}$ are capable to resettle resonant energy states from $\mathrm{Er}^{3+}$ ions above the state ${ }^{4} \mathrm{I}_{13 / 2}$. Therefore, the cerium ions act as constraints impeding the up-conversion process in the nanoparticle. Thus, the maximum efficiency of nanoparticle excitation is achieved with the following radiative decay at $1530 \mathrm{~nm}$ wavelength [2].
\end{abstract}

*Corresponding author: haidukov_11@mail.ru 
Hexagonal shape nanocrystals have a size distribution in the range $40-80 \mathrm{~nm}$ (see the inset in Fig. 1). The photoluminescence of nanoparticles has been studied using spectrofluorimeter Fluorolog 3 (HJY, France) under the excitation by semiconductor laser at $977 \mathrm{~nm}$. The luminescence spectra, measured at room temperature, have an intense line in the NIR (see Fig. 1). The utilization of more effective $\beta-\mathrm{NaLuF}_{4}$ matrix in comparison to $\beta-\mathrm{NaYF}_{4}$ makes possible to enhance the quantum yield from 2 to $6 \%$. The introduction of cerium ions into the nanocrystal matrix allows to increase the efficiency of transition ${ }^{4} \mathrm{I}_{13 / 2} \rightarrow{ }^{4} \mathrm{I}_{15 / 2}$ up to 6 times. The transition lifetime is $6.9 \mathrm{~ms}$ (see Fig. 3).
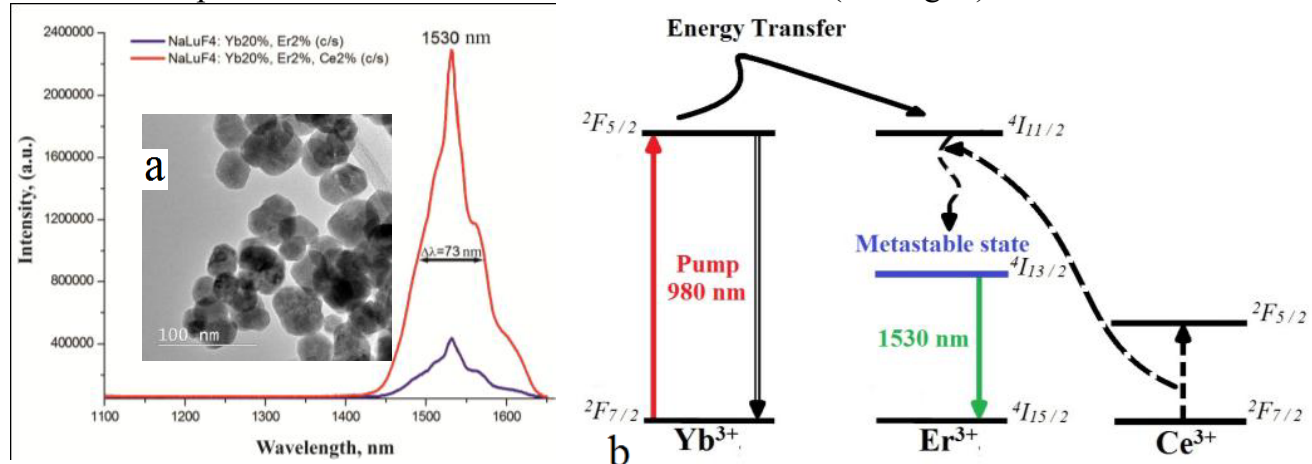

Fig. 1. TEM image (the inset) and the PL spectra of synthesized $\beta-\mathrm{NaLuF}_{4}: \mathrm{Er}^{3+}$, $\mathrm{Yb}^{3+}, \mathrm{Ce}^{3+}$ and $\beta-\mathrm{NaLuF}_{4}: \mathrm{Er}^{3+}, \mathrm{Yb}^{3+}$

Fig. 2. Schematic energy transfer processes in NaYF4 crystal between $\mathrm{Er}^{3+}, \mathrm{Yb}^{3+}$ and $\mathrm{Ce}^{3+}$. nanocrystals under excitation at $977 \mathrm{~nm}$.

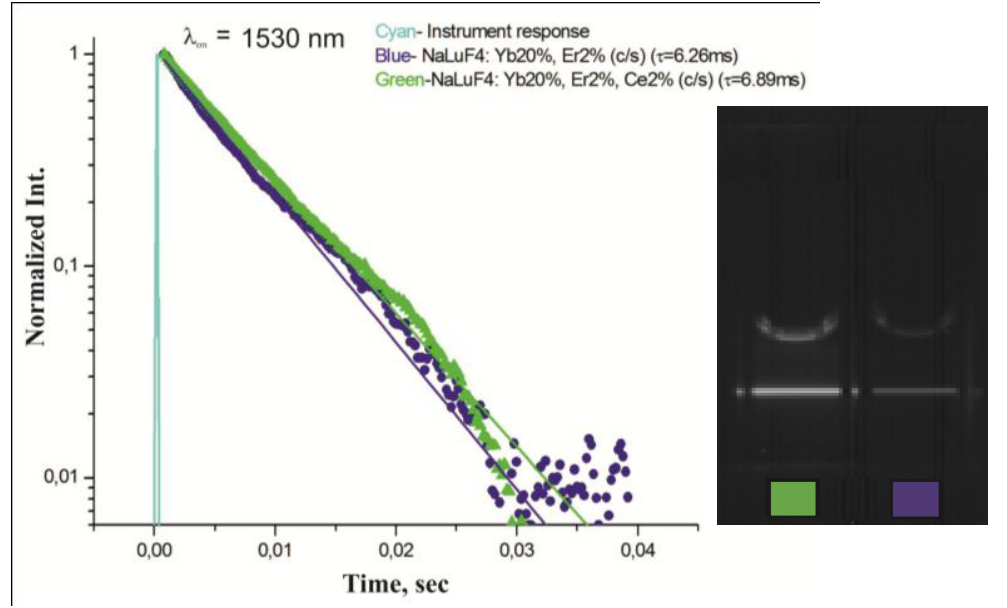

Fig. 3. Kinetics of photoluminescence decay of $\beta-\mathrm{NaLuF}_{4}: \mathrm{Er}^{3+}, \mathrm{Yb}^{3+}, \mathrm{Ce}^{3+}$ and $\beta-\mathrm{NaLuF}_{4}$ : $\mathrm{Er}^{3+}, \mathrm{Yb}^{3+}$ around $1.5 \mu \mathrm{m}$ under the excitation at $977 \mathrm{~nm}$. Excitation pulse length duration is $80 \mu \mathrm{s}$. The inset demonstrates two cuvettes with nanoparticles dissolved in dichloromethane $\left(\mathrm{CH}_{2} \mathrm{Cl}_{2}\right)$ and illuminated by $975 \mathrm{~nm}$ laser beam.

Results of the conducted research indicate that the synthesized nanoparticles are a promising platform for fabrication of compact waveguide amplifiers for $\mathrm{C}$ - band.

The work was supported by Grant RFBR \# 16-32-00935-mol_a.

\section{References}

1. A.N. Generalova et al., Nanoscale 7, 1709 (2015)

2. X. Zhai et al., J. of Materials Chemistry C 3, 1555 (2013) 